\title{
Integrating Sentinel-2 Data and PAPCAR Model to Map Water Erosion: Case of Beni Boufrah Watershed
}

\author{
1. Labbaci, A. ${ }^{1}$, Marghadi, $\mathrm{S}^{2}$, Laaribya, $\mathrm{S}^{3}$, Moukrim, $\mathrm{S}^{4}$ \\ 1. Ibn Zohr University, Faculty of Sciences, Geology Department, Geomaterials Laboratory, P.O. \\ Box: 8106 Agadir, Morocco
}

2. National Forest Engineers School, P.O. Box: 11000 Salé, Morocco

3. Chouaib Doukkali University, Faculty of humanities and social sciences, Avenue des Facultés, P.O. Box: 24000, El Jadida, Morocco

4. High Commission of Water Forests and Combating Desertification, P.O. Box: 10000 Rabat, Morocco

Correspondence: Adnane Labbaci, email: labbaciadnane@gmail.com

\begin{abstract}
Water erosion causes significant economic losses linked mainly to the silting up of dams and losses in soil productivity, these consequences will increase if soil and water conservation actions associated with development actions are not undertaken. The present work aims to evaluate the water erosion in the basin of the Beni Boufrah located in the Northern part of Morocco. The hierarchy of this basin in plot according to the degrees and the tendencies of the erosion was made using the qualitative PAP/CAR approach (Programme d'Actions Prioritaires/Centre d'Activités Regionales) which is based on the integration of the factors influencing the water erosion, such as the slope, lithology and/or pedology, vegetation cover and land use. This work was conducted in three stages, the first one being predictive based on the analysis of the natural factors influencing water erosion and the processing of databases of developed maps. The second so-called descriptive stage is based on the mapping of different forms and processes of soil loss that occur in the study area. The last step, it allows the integration and the combination of the results of the two previous steps. Its purpose is to provide a precise cartographic product that reflects the reality of the state of soil degradation and the future evolution of erosion. The consolidated erosion map shows that more than half of the basin area (53\%) is affected by medium-level erosion, $13 \%$ is affected by high erosion level, and $15 \%$ is affected by low-level water erosion. Low-intensity erosion occurs along the river in areas where the slope and lithology favour runoff. The trend map is the final result of the integration phase, it describes erosion trends in the different parts of the basin and is, therefore, a tool to guide decisions on land use planning and tillage methods to limit the risk of water erosion in the basin.
\end{abstract}

Keywords: Oued Beni Boufrah, water erosion, PAP/CAR, erosive states, erosion trend.

\section{Introduction}

Water erosion is the most serious form of physical soil degradation affecting Mediterranean 
coastal areas, its major impacts on the environment are the result of interactions between bioclimatic factors and ecologically inappropriate and destabilizing human interventions (PAP/RAC, 1998). Water erosion is a process that takes away and redistributes soil. It is defined as the detachment and transport of soil particles from its original location by water to a deposition site. This mechanism occurs because of rain and surface runoff in three stages: detachment, transport, and sedimentation.

Erosion and soil degradation have major consequences on the natural environment and development. The hydrological consequences of this degradation are significant and sometimes catastrophic. In semi-arid or Mediterranean regions, soil degradation is expressed by a decrease in vegetation density, loss of soil (long-term loss of productivity), loss of organic matter and retention capacity, increased landscape mineralization. The variation and interaction of causal factors in water erosion results in soil degradation that affects soil heritage and has serious economic, human, and ecological consequences, SADIKI, A. (2005).

The objective of this study is to address the problem of water erosion in the Beni Boufrah watershed, through qualitative mapping using GIS, and adopting the PAP/CAR model, which focused on the integration of factors influencing water erosion, such as slope, hydrographic network, soil type, lithological material, and type of vegetation cover. The final product of this mapping will provide information on current erosion in its different forms, intensities, and evolutionary trends.

\section{Materials and Methods}

\subsection{Study Area}

The study area is part of the Central Rif not far from El Hoceima where the hills and low mountains offer a pattern of irregular slopes in relation to the structural scheme and the importance of dissection and Quaternary heritages. This complexity has been marked by very complex geology characterized by numerous bedrock layers that have shaped the current Rifain landscape. The watersheds of the study site cover an area of 94409 ha. Altitudes vary from one area to another, ranging from 8 to $1800 \mathrm{~m}$, but remain very high for the entire study area. 


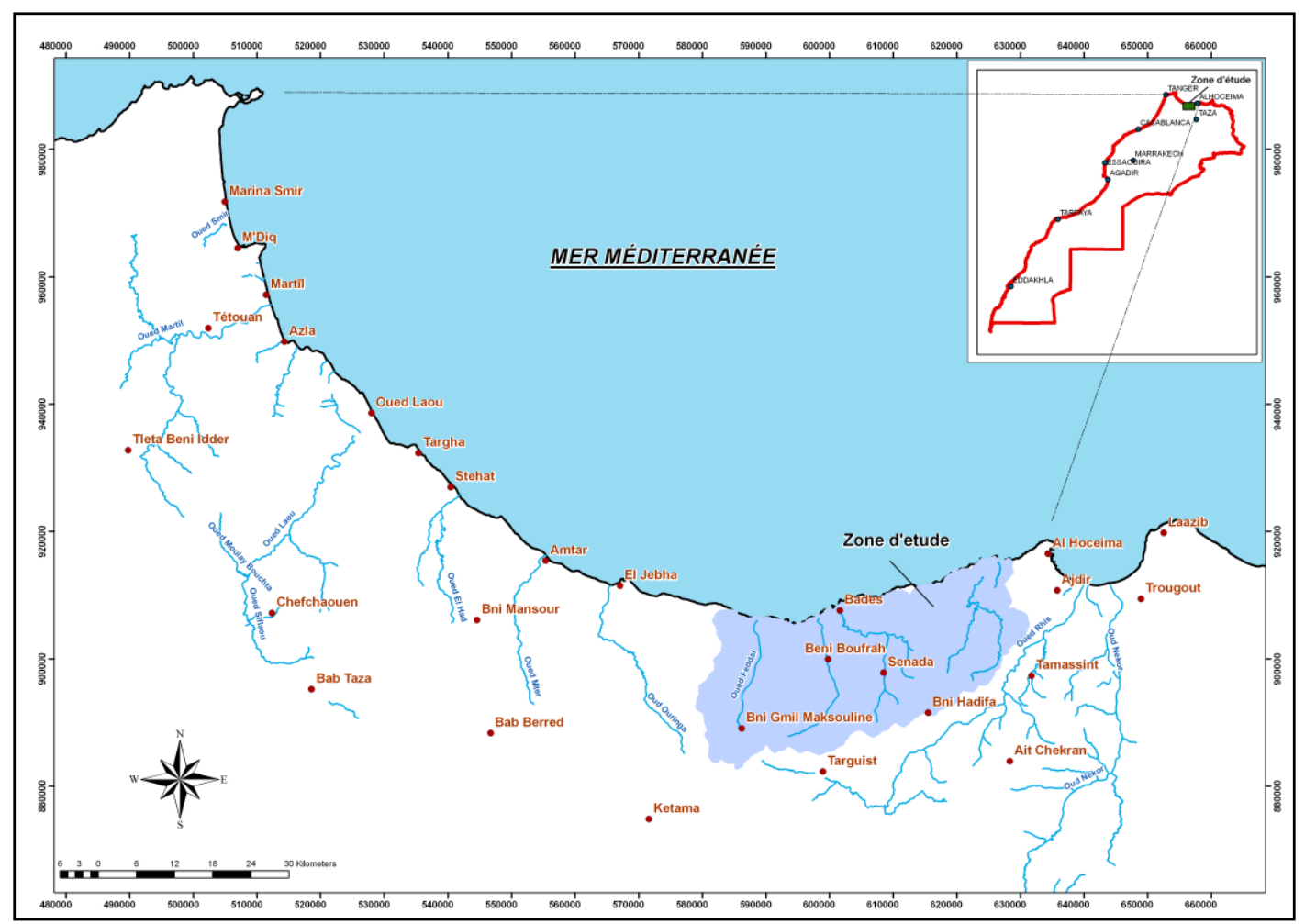

Figure 1: Localization map of Beni Boufrah watershed

The precise delimitation of the catchment areas was based on topographic maps and on the hydrographic network. This work will be refined using the georeferenced Digital Elevation Model (DEM) and the ARC Hydro Geographic Information System of the ArcGIS software. This tool made it possible to delimit the sub-watersheds according to their importance and size as well as the importance of its water network and its role in the hydrological functioning of the watershed.

Rainfall is a factor that allows us to characterize a climate, not only by the annual amount of water collected but also its importance is strongly correlated to the soil water balance and the behavior of plants. In the study area, climate analysis was carried out on the basis of rainfall observations taken at 9 stations located in various positions. The annual averages of the reference stations range from $300 \mathrm{~mm}$ to $800 \mathrm{~mm}$. the maximum precipitation is collected during the winter and a significant dry period ranging from 3 to 5 months, with the wettest months for all stations from winter to early spring (March). In general, all stations have their minimum precipitation during the summer period.

The land cover map was derived from the Sentinel-2 images as well as from ground truth surveys. Taking into account the nature of the different formations and their relevance to the erosive phenomenon, a supervised classification was adopted to facilitate the mapping work and to be able to distinguish the different strata. The land use map has the following classes: natural forest formations, secondary species formations, rangelands with sometimes sparse vegetation for pastoral use, irrigated terraces with crops, cereal and tree crops, and rural settlements. 


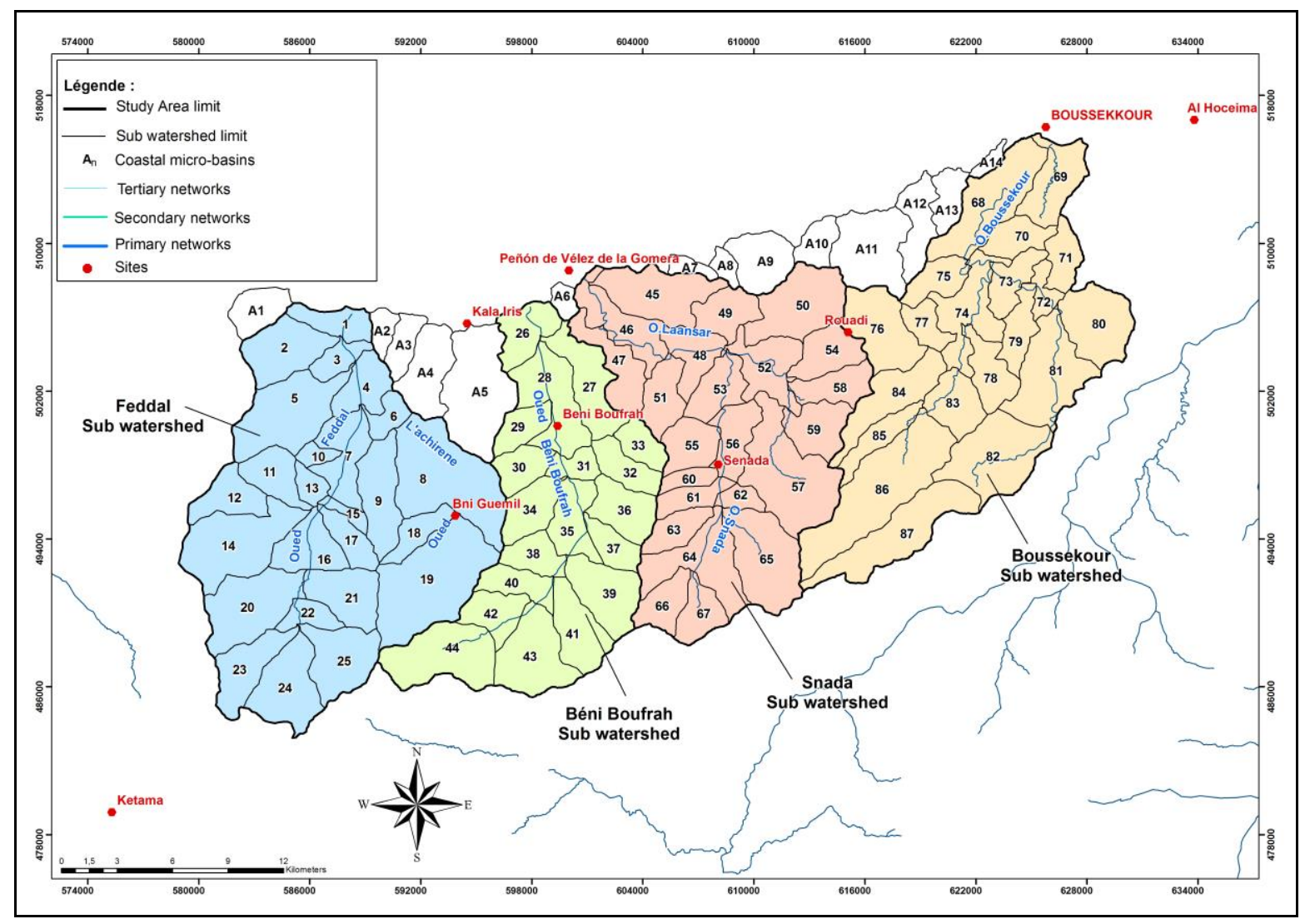

Figure 2: Localization map of Beni Boufrah sub-watershed

The PAP/RAC technique for land degradation assessment is a methodological tool and a practical source of information. However, in order to improve its performance, this work presents the application of this technique as an attempt to disentangle the interdependence of the causal factors of risk was undertaken by analyzing the correlations between the parameters.

The methodological steps of the PAP/RAC model three approaches. First, the predictive approach that controls erosion based on thematic mapping of factors (slope, lithology, land use, and degree of vegetation cover). This approach is completed by the deduction of the erosive state map which gives an idea of the degree of erosion throughout the area. Second, the descriptive approach gives a real picture of the different forms of erosion located in the study area and their degrees of exposure to degradation. Third, the integration approach is the superposition of the maps of erosive states obtained by thematic mapping and the map of erosion patterns obtained by direct descriptive mapping of erosion patterns in the field or by satellite images.

\section{Results and discussions}

\subsection{Predictive approach}

The expected result of this phase is the realization of the map of erosive states obtained by integrating several factors into the soil erosion equation. Each factor contributes to a certain 
degree to the different erosive states. The objective of this phase is to process erosion factor maps in three steps:

\section{Production of the e rodibility map}

Soil erodibility expresses the potential of a rock outcrop to provide elements for erosion. Therefore, the friability of a substrate and the percentage of the slope must be considered. The slope map is based on the elevation of this region, and classified by the PAP/RAC guidelines according to the following table:

Table 1: Slope classes according to PAP/CAR

\begin{tabular}{|c|c|}
\hline PAP/CAR code & Slope type \\
\hline 1 & None to low $(0-3 \%)$ \\
\hline 2 & Moderate $(3 \%-12 \%)$ \\
\hline 3 & Abrupt $(12 \%-20 \%)$ \\
\hline 4 & Very steep $(20 \%-35 \%)$ \\
\hline 5 & Extreme $(>35 \%)$ \\
\hline
\end{tabular}

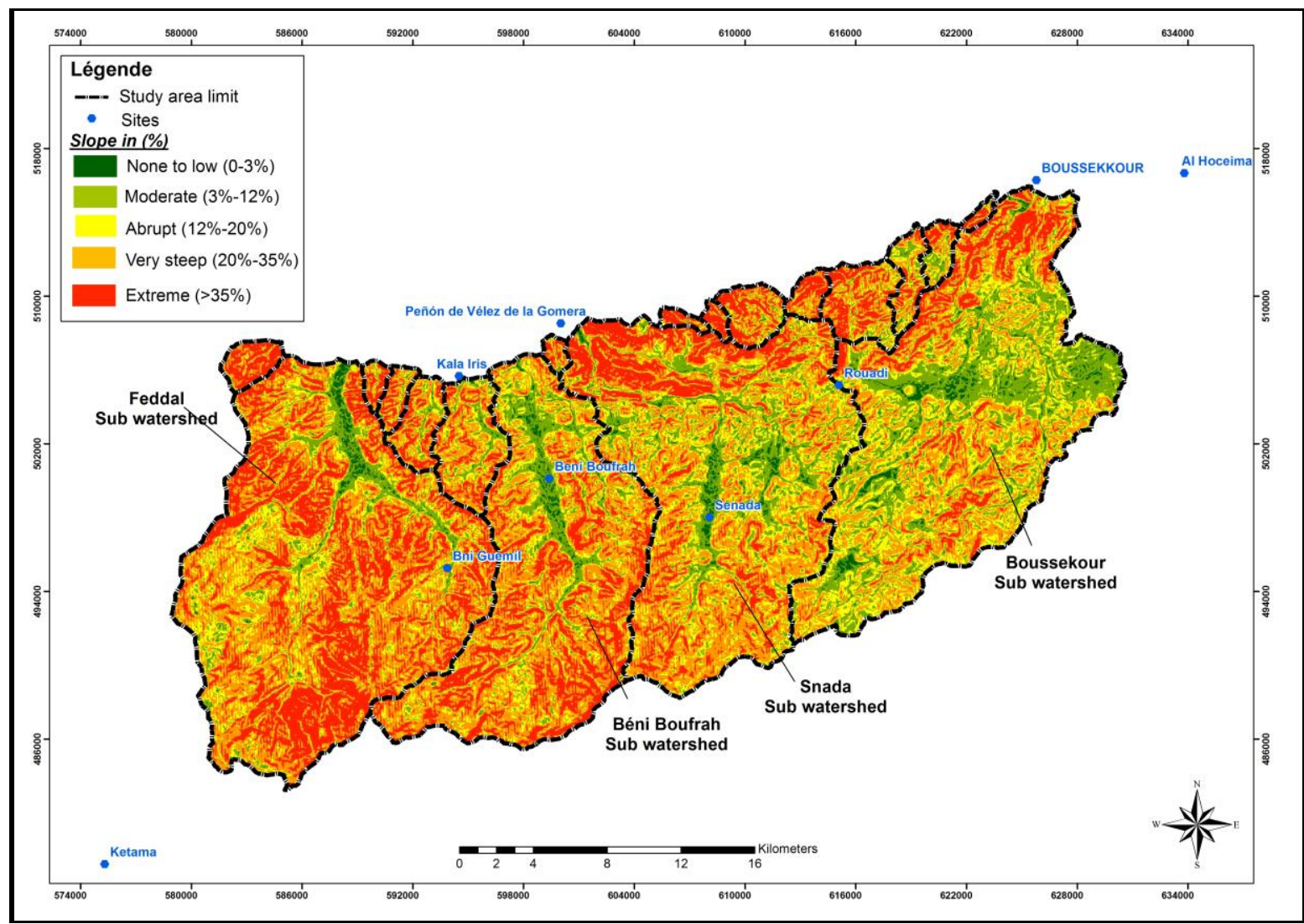

Figure 3: Slope map of Beni Boufrah watershed

The dominance of class 20 to $35 \%$, which extend over an area of $40 \mathrm{~km}^{2}$ of the study area, and therefore occupy $42 \%$ of its total surface area. The average slopes (3-12\%) extend over $13 \mathrm{~km}^{2}$ and occupy $14.2 \%$ of the area. 
The Lithofacies map describes the distribution of outcrops according to their degree of friability. These are divided into 5 classes and assigned a code that designates their degree of friability. More than $73 \%$ of the watersheds have sedimentary rocks or soils that are slightly or moderately compacted with Sediments or soft, non-cohesive and detrital material (figure 5). The friability map shows that the catchment areas are characterized by relatively less compact materials related to marl and alluvial formations.

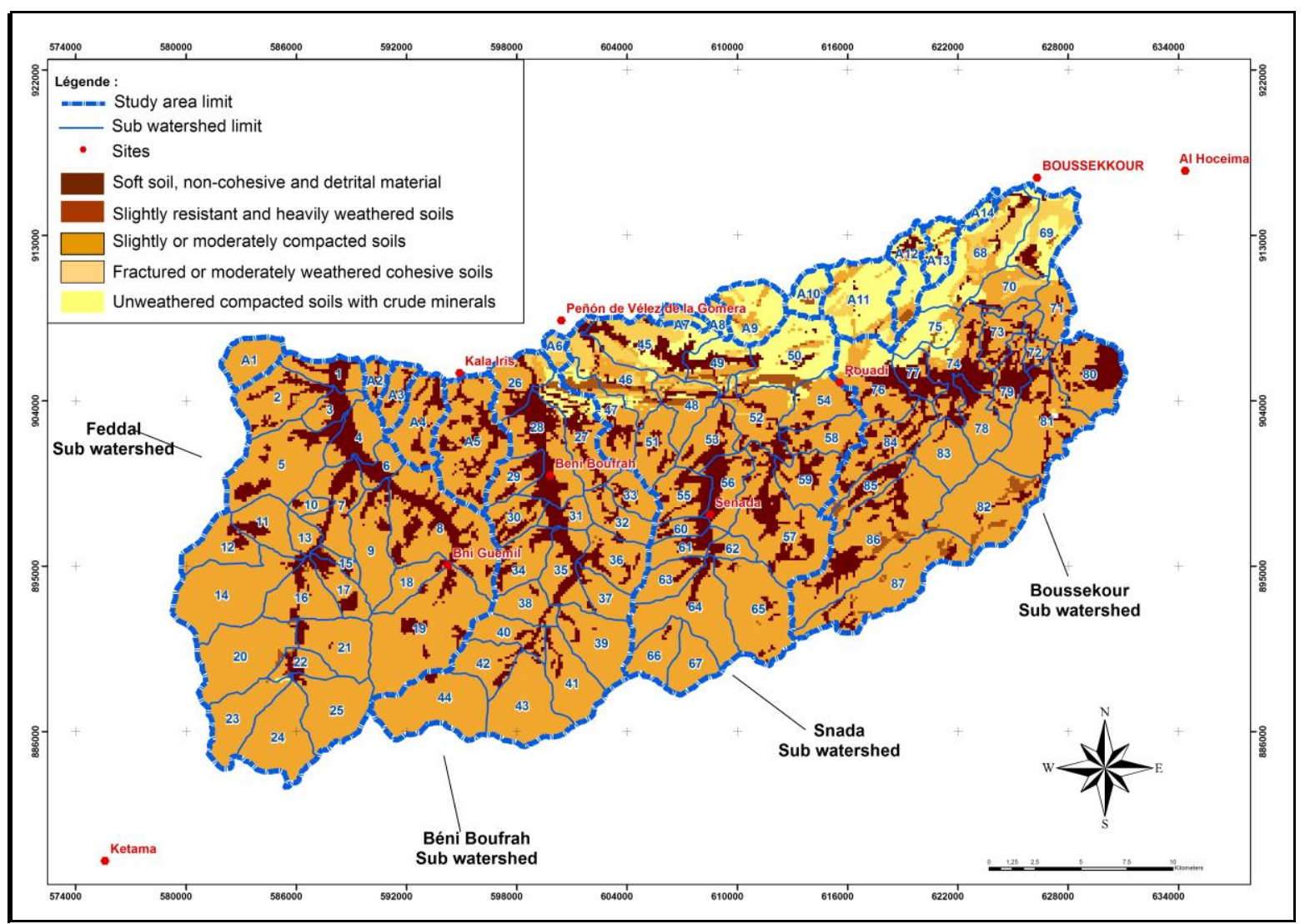

Figure 5: Lithofacies map of Beni Boufrah watershed

The erodibility Map is the result of the superposition of the Lithofacies map and the Slope map, according to the following matrix:

Table 2: Soil Erodibility Matrix

\begin{tabular}{|c|c|c|c|c|c|}
\hline \multirow{2}{*}{ Slope class } & \multicolumn{5}{|c|}{ Lithofacies classes } \\
\cline { 2 - 6 } & $1(\mathrm{a})$ & $2(\mathrm{~b})$ & $3(\mathrm{c})$ & $4(\mathrm{~d})$ & $5(\mathrm{e})$ \\
\hline 1 & 1 & 1 & 1 & 1 & 2 \\
\hline 2 & 1 & 1 & 2 & 3 & 3 \\
\hline 3 & 2 & 2 & 3 & 4 & 4 \\
\hline 4 & 3 & 3 & 4 & 5 & 5 \\
\hline 5 & 4 & 4 & 5 & 5 & 5 \\
\hline
\end{tabular}

The erodibility classes obtained by applying this matrix are classified by the PAP/RAC guidelines according to the following table: 
Table 3: Degrees of erodibility according to PAP/CAR

\begin{tabular}{|c|c|}
\hline PAP/CAR code & Degrees of e rodibility \\
\hline 1 & Low $(\mathrm{EN})$ \\
\hline 2 & Moderate $(\mathrm{EB})$ \\
\hline 3 & Average (EM) \\
\hline 4 & High (EA) \\
\hline 5 & Extreme $(\mathrm{EX})$ \\
\hline
\end{tabular}

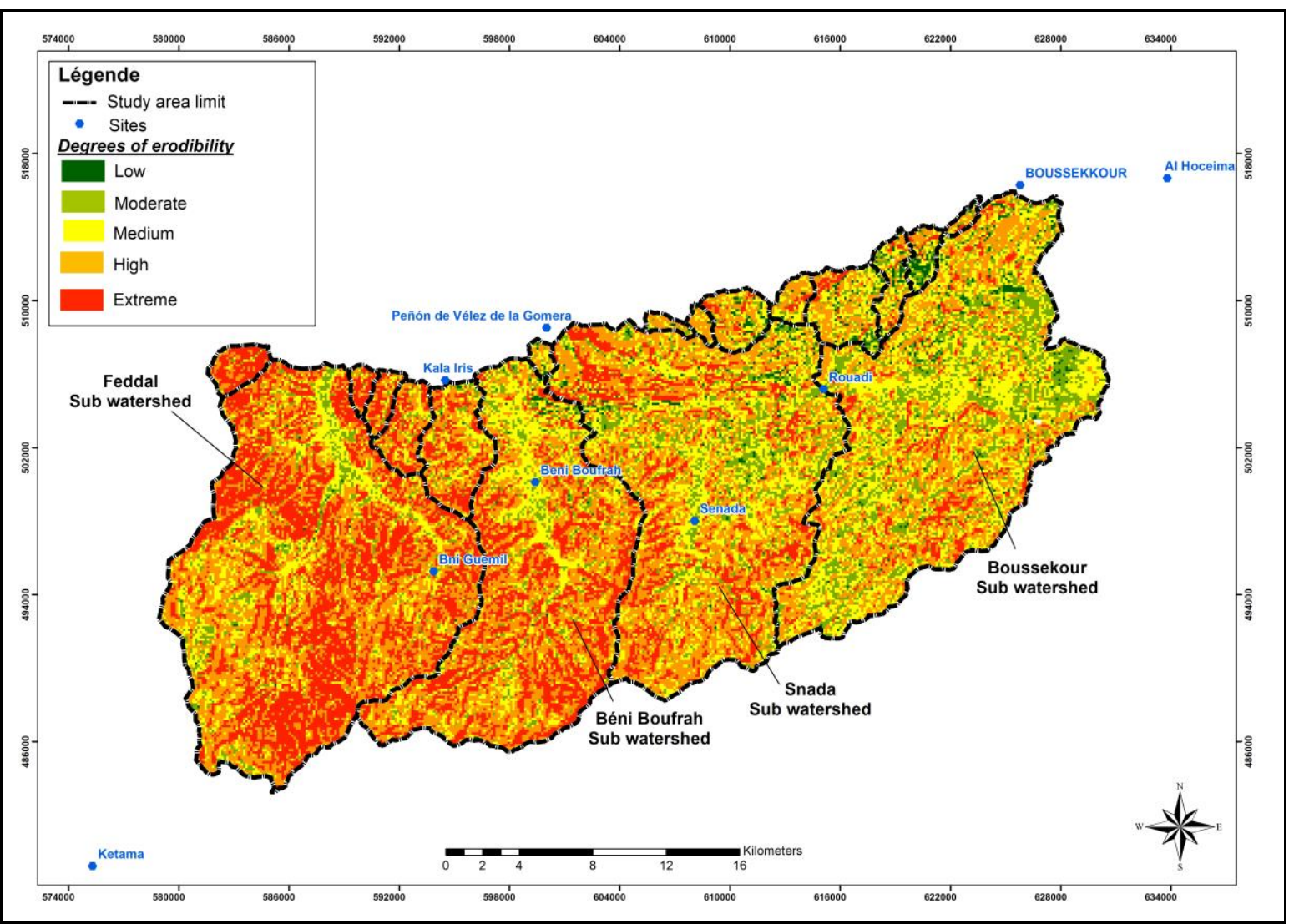

Figure 6: Erodibility map of Beni Boufrah watershed

Table 4: Distribution of erodibility classes according to PAP/CAR

\begin{tabular}{|c|c|c|}
\hline Degrees of e rodibility & Area (ha) & \% \\
\hline Low (EN) & 2475,71 & 2,62 \\
\hline Moderate (EB) & 13470,63 & 14,27 \\
\hline Average (EM) & 22907,46 & 24,26 \\
\hline High (EA) & 46007,43 & 48,73 \\
\hline Extreme (EX) & 9547,78 & 10,11 \\
\hline Total & $\mathbf{9 4 4 0 9 , 0 2}$ & $\mathbf{1 0 0 , 0 0}$ \\
\hline
\end{tabular}

The analysis of the results of the distribution of the different erodibility classes shows that more than $97 \%$ of all watersheds represent moderate to extremely erodible classes. The erodibility map (Figure 6) also confirms this; the surface area of the basins represents a very 
high erodibility relative to steeply sloping areas where the materials are relatively friable and less compact, the remaining $3 \%$ are occupied by low degrees of erodibility located in areas with low slopes and relatively more compact materials.

The passage of compacted rocks to loosen sediments shows an increase in the erosive potential of watersheds influenced by the degree of slope. As a result, erodibility is always extreme when the slope is relatively steep and/or the terrain is of low resistance.

\section{De velopment of the soil protection map}

The elaboration of the soil protection map is based on the superposition of the land use map and the cover density map according to a matrix proposed by PAP/CAR. The land cover map was developed from the satellite image (Sentinel-2) of this region and classified by the PAP/CAR guidelines based on the following table:

Table 5: Land use class

\begin{tabular}{|c|l|}
\hline Classes & \multicolumn{1}{|c|}{ Land use } \\
\hline 1 & Culture in dry or bare ground \\
\hline 2 & Arboriculture and reforestation \\
\hline 3 & Intensive cultivation near housing \\
\hline 4 & Forests \\
\hline 5 & Dense Covered Matorrals \\
\hline
\end{tabular}

According to the analysis of these results, the class of intensive crops near housing represents $52.74 \%$, followed by that of forests with $31.51 \%$. This can be explained by the geological, morphological and climatic nature of the study area. The map obtained (figure 7) shows that the location of the most important class is in the upstream part of the catchment areas. Forest lands and matorrals occupy the northern slopes of the basins and the downstream part. 


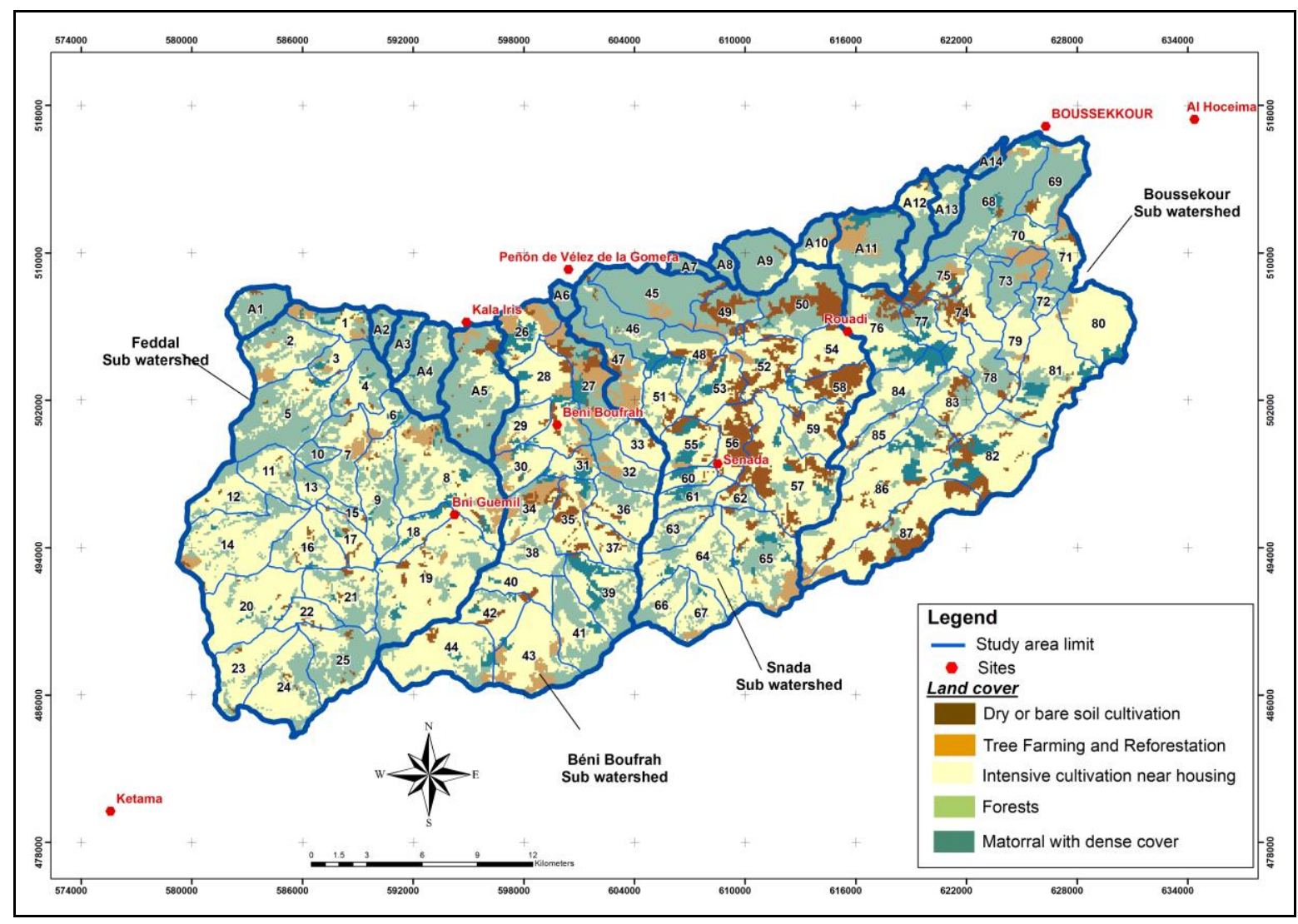

Figure 7: Map of the different land use classes

To classify the degree of vegetation cover, the PAP/RAC guidelines propose 4 classes:

Table 6: Degree of vegetation cover classes

\begin{tabular}{|c|l|}
\hline Classes & \multicolumn{1}{|c|}{ Vegetation Cover (\%) } \\
\hline 1 & Below $25 \%$ \\
\hline 2 & $25 \%-50 \%$ \\
\hline 3 & $50 \%-75 \%$ \\
\hline 4 & More than $75 \%$ \\
\hline
\end{tabular}

The classification of the degree of vegetation cover of the watersheds is based on the observation of the satellite image of this region, whose trees are considered as a medium density class (25\%-50\%), the other occupations are considered as a low density class (Less than 25\%).

The map of the degree of vegetation cover (figure 8) shows the presence of two classes (1 and 2 ), with low and medium density, respectively. Low density is relative to any surface where vegetation is less than $25 \%$, which occupies almost $64 \%$ of the total surface area of the basins. The average density of the vegetation cover is represented by $22.61 \%$ of these basins, this class is relative to areas where the degree of vegetation cover takes a value between $25 \%$ and $50 \%$. 


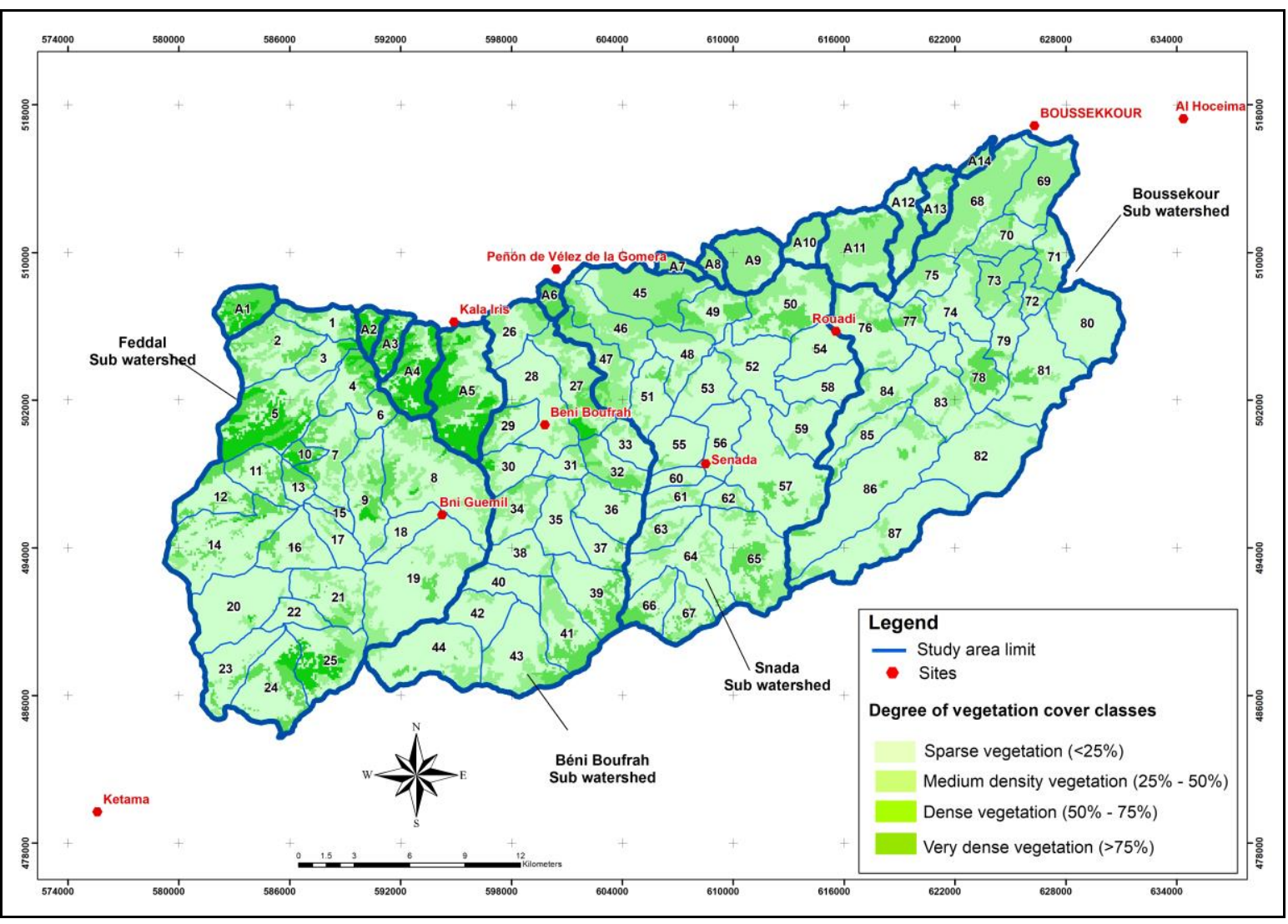

Figure 8: Map of the degree of vegetation cover classes

The protection map is created by superimposing the map of land use and the degree of vegetation cover. The polygons resulting from the superposition of these 2 reference maps are classified according to the matrix in Table 7:

Table 7: Soil protection matrix

\begin{tabular}{|c|c|c|c|c|}
\hline \multirow{2}{*}{ Land use } & \multicolumn{4}{|c|}{ Vegetation cover } \\
\cline { 2 - 5 } & 1 & 2 & 3 & 4 \\
\hline 1 & $5(\mathrm{MB})$ & $5(\mathrm{MB})$ & $4(\mathrm{~B})$ & $4(\mathrm{~B})$ \\
\hline 2 & $5(\mathrm{MB})$ & $5(\mathrm{MB})$ & $4(\mathrm{~B})$ & $3(\mathrm{M})$ \\
\hline 3 & $3(\mathrm{M})$ & $2(\mathrm{~A})$ & $1(\mathrm{MA})$ & $1(\mathrm{MA})$ \\
\hline 4 & $4(\mathrm{~B})$ & $3(\mathrm{M})$ & $2(\mathrm{~A})$ & $1(\mathrm{MA})$ \\
\hline 5 & $5(\mathrm{MB})$ & $4(\mathrm{~B})$ & $3(\mathrm{M})$ & $2(\mathrm{~A})$ \\
\hline 6 & $5(\mathrm{MB})$ & $4(\mathrm{~B})$ & $3(\mathrm{M})$ & $2(\mathrm{~A})$ \\
\hline
\end{tabular}

The different classes of soil protection according to the PAP/RAC guidelines are summarized in the following table: 
Table 8: Soil protection degree classes according to PAP/RAC

\begin{tabular}{|c|l|}
\hline Classes & \multicolumn{1}{|c|}{ Land use } \\
\hline 1 & Very high (MA) \\
\hline 2 & High (A) \\
\hline 3 & Medium (M) \\
\hline 4 & Low (B) \\
\hline 5 & Very low (MB) \\
\hline
\end{tabular}

The map of soil protection classes (figure 9) shows that the most frequent value is the average protection value $(3 \mathrm{M})$ with a percentage of $70.68 \%$ of the total surface area of the basins. So, the vegetation basins are generally poorly protected.

Table 9: Distribution of erodibility classes according to PAP/CAR

\begin{tabular}{|c|c|c|}
\hline Classes & Area (ha) & $\%$ \\
\hline 1 & 3591,89 & 3,80 \\
\hline 2 & 8512,18 & 9,02 \\
\hline 3 & 66727,47 & 70,68 \\
\hline 4 & 692,29 & 0,73 \\
\hline 5 & 14885,19 & 15,77 \\
\hline Total & $\mathbf{9 4 4 0 9 , 0 1}$ & $\mathbf{1 0 0 , 0 0}$ \\
\hline
\end{tabular}

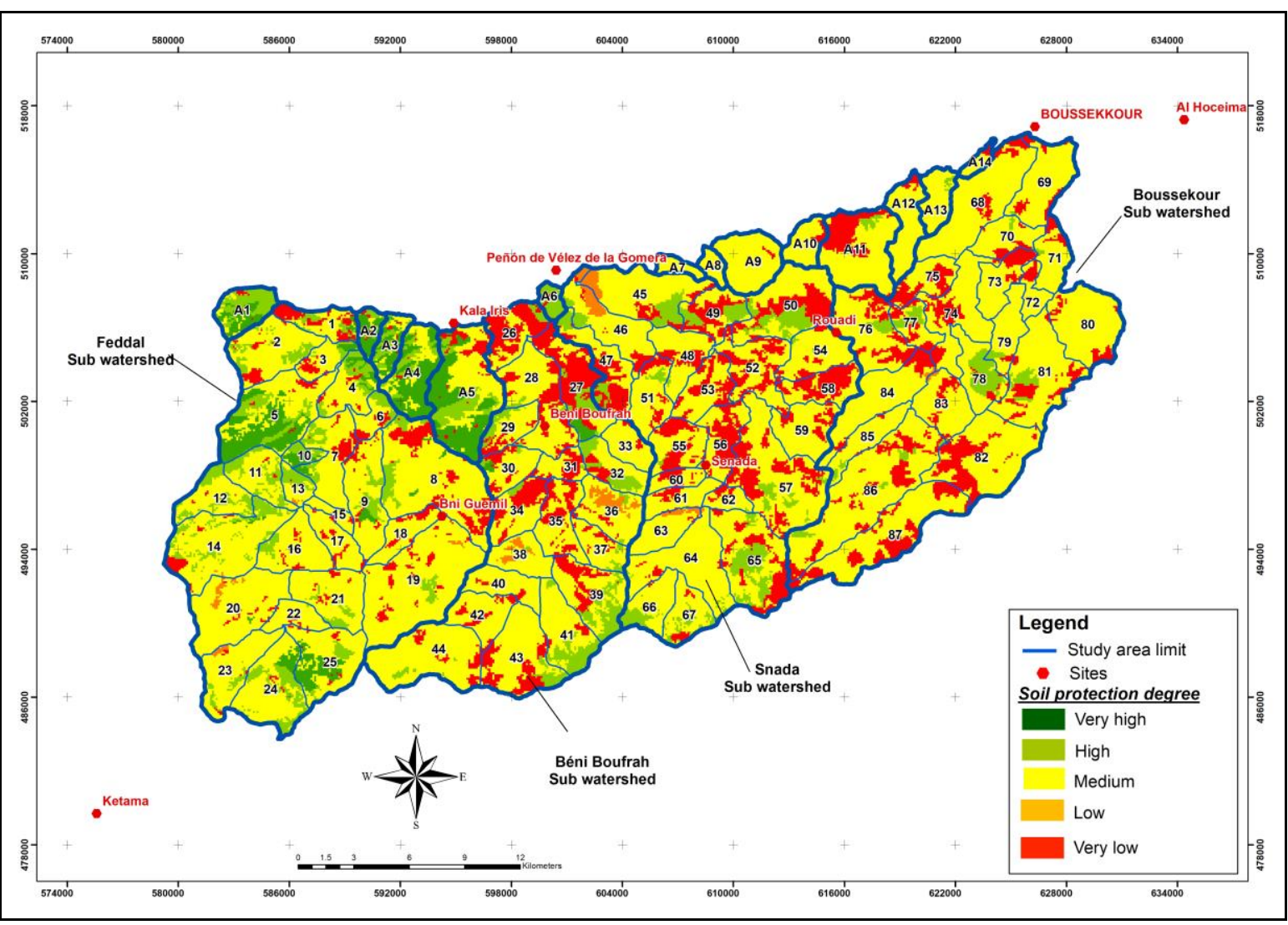

Figure 9: Soil Protection Map of the Catchment Areas according to PAP/RAC 


\section{Map of Erosive States}

The map of erosive states (figure 10) is the final product of the predictive phase, resulting from the superposition of the erodibility map and the map of soil protection degrees. The resulting polygons are classified according to the matrix in the following table:

Table 10: Matrix of soil erosion states according to PAP/RAC

\begin{tabular}{|c|c|c|c|c|c|}
\hline \multirow{2}{*}{$\begin{array}{c}\text { Degree of Soil } \\
\text { Protection }\end{array}$} & \multicolumn{5}{|c|}{ Degree of erodibility } \\
\cline { 2 - 6 } & $1(\mathrm{EN})$ & $2(\mathrm{~EB})$ & $3(\mathrm{EM})$ & $4(\mathrm{EA})$ & $5(\mathrm{EX})$ \\
\hline $1(\mathrm{MA})$ & 1 & 1 & 1 & 2 & 2 \\
\hline $2(\mathrm{~A})$ & 1 & 1 & 2 & 3 & 4 \\
\hline $3(\mathrm{M})$ & 1 & 2 & 3 & 4 & 4 \\
\hline $4(\mathrm{~B})$ & 2 & 3 & 3 & 5 & 5 \\
\hline $5(\mathrm{MB})$ & 2 & 3 & 4 & 5 & 5 \\
\hline
\end{tabular}

The polygons obtained are classified by PAP/CAR according to the following table:

Table 11: Erosive state classes according to PAP/RAC

\begin{tabular}{|c|l|}
\hline Classes & \multicolumn{1}{c|}{ Degrees of Erosive States } \\
\hline 1 & Very low \\
\hline 2 & Low \\
\hline 3 & Notable \\
\hline 4 & High \\
\hline 5 & Very high \\
\hline
\end{tabular}

The map of the erosive states of the watersheds shows the dominance of the high and notable classes (4) and (3), which are in areas with high slopes, and/or the lithology is of a friable nature. The low (2) and very low (1) erosion degree class occupies small areas. 


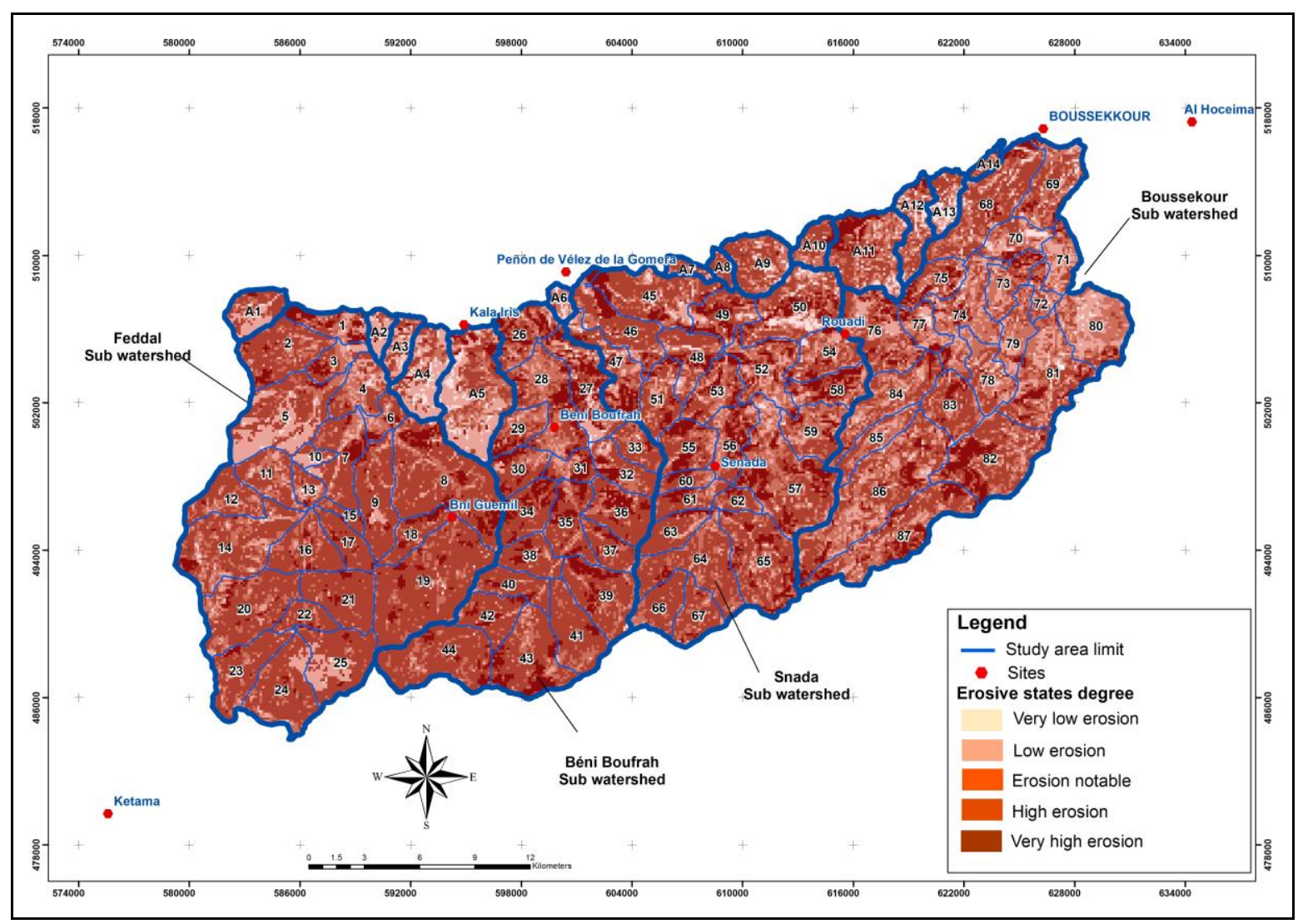

Figure 10: Map of the erosive states of the watersheds according to PAP/CAR

\subsection{Des criptive approach}

This phase is based on the mapping delimitation of the erosion patterns that characterize all watersheds according to the PAP/RAC guidelines, which provide written indications to indicate the erosion pattern, and figures to indicate the intensity of the process:

Erosion patterns in the basins are determined by mapping from the satellite image and topographic map of the study area. The resulting map (figure 11) shows that the basins are threatened by the following forms of soil degradation: 


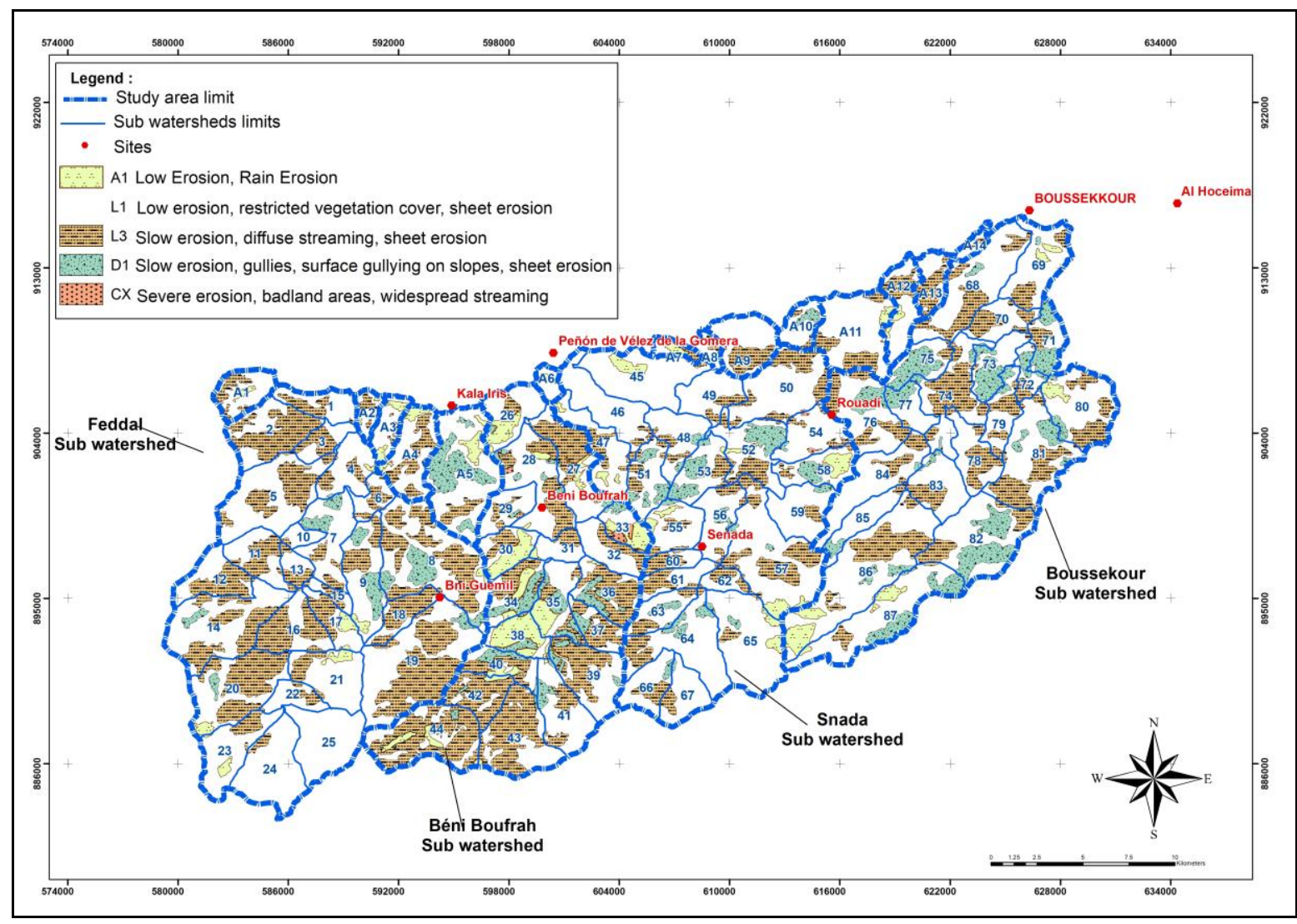

Figure 11: Maps of the Different Forms of Water Erosion in the Catchment Areas according to PAP/RAC

Table 12: Percentage of water erosion forms in watersheds

\begin{tabular}{|l|l|c|c|}
\hline \multicolumn{1}{|c|}{ Form of erosion } & \multicolumn{1}{c|}{ Code } & Area (ha) & \% \\
\hline Concentrated erosion/Refinement & CX & 98,83 & 0,10 \\
\hline Sheet erosion & L3 & 26078,80 & 27,62 \\
\hline Low erosion & L1 & 56651,92 & 60,01 \\
\hline Linear erosion/Rigoles & D1 & 7431,23 & 7,87 \\
\hline Rain erosion & A1 & 4148,40 & 4,39 \\
\hline \multicolumn{2}{|c|}{ Total } & $\mathbf{9 4 4 0 9 , 0 2}$ & $\mathbf{1 0 0 , 0 0}$ \\
\hline
\end{tabular}

\subsection{Inte gration approach}

The integration phase complements the results obtained during the predictive phase with descriptive data on erosion processes. The purpose of this step is to produce the final map identifying and evaluating both potential erosion (Erosive Status) and current erosion in its different forms, intensities, and evolutionary trends. The consolidated erosion map (figure 12) is the result of the superposition of the predictive phase erosion states map (figure 10), and the descriptive phase erosion forms map (figure 11). The product of this calibration is a database that targets priority areas requiring conservation and erosion control actions. 


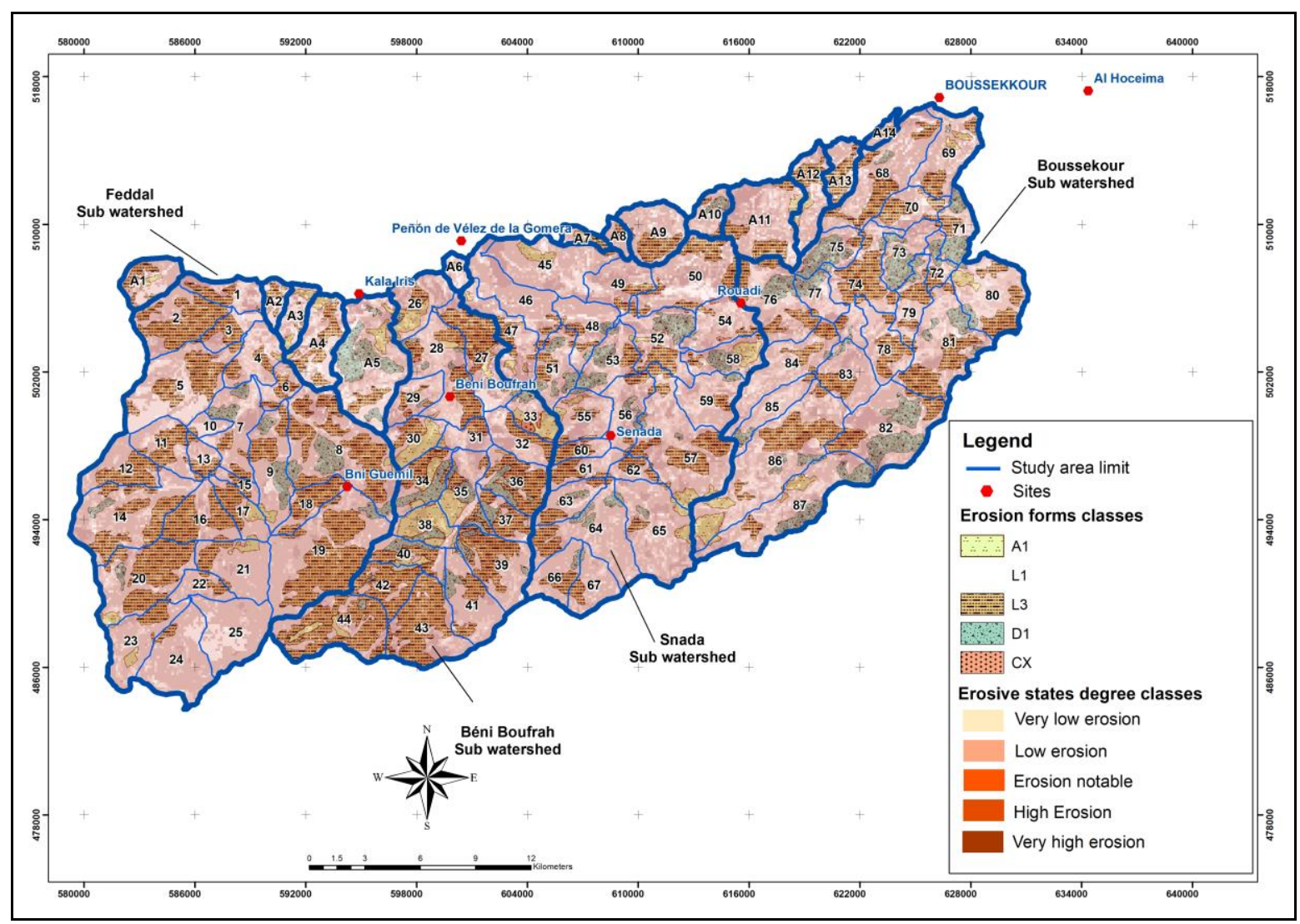

Figure 12: Consolidated map of water erosion in the catchment areas according to PAP/RAC

The most dominant class is that of high intensity sheet erosion (L1), occupying $1 / 3$ of these basins $(31 \%)$. This class is characteristic of areas of medium slope, compact lithology, and medium density vegetation cover. The high sheet erosion class (L3) occupies $16 \%$ of the surface area of the basins, it is located on low to moderate slopes, a substrate promotes rustle, and a low to medium vegetation cover. It is from this stage that the water begins to run dry and form gullies.

The class of significant sheet erosion occupies $15 \%$ of the total surface area of the basins. It is generally found on areas of low slope where the sediments are silty-clayey. The erosion class concentrated in low-intensity ravines occupies a very small portion $(0.15 \%)$ of our basin, it is generally located next to the flows of the wadi... where the slope is more important (4-13\%), and/or the substrate and impermeable (marls, clayey silts) favoring rustle. The other classes are poorly represented, as they occupy only $4.37 \%$ of the total surface area of this basin.

It should be noted that the basins do not have areas fully protected against water erosion, this is due to its situation in a very rugged region characterized by the absence of dense vegetation cover (forests, dense shrubs), which makes the latter totally exposed to the risks of water erosion at these different intensities.

The unstable areas affected by water erosion (groundwater and ravines) occupy almost 95\%, the rest of the basin $(5 \%)$ is occupied by rainwater erosion and concentrated erosion. The location of these basins in a mountain area (medium to steep slopes) does not prevent the latter 
from presenting a risk of erosion, which confirms the important role of vegetation cover (type and density) in protecting the soil against water erosion. In addition to the production of the consolidated map, this phase makes it possible to determine trends in the surface evolution of water erosion. These trends are determined according to a matrix that combines the states of erosion, and the actual forms of erosion.

Table 13: Matrix of erosion trends according to PAP/RAC

\begin{tabular}{|l|c|c|}
\hline \multirow{2}{*}{ Erosive state } & \multicolumn{2}{|c|}{ Forms of erosion } \\
\cline { 2 - 3 } & Minor forms of erosion SP, L, D & Major forms of erosion C1.........CX \\
\hline Very low erosion & 1 & 3 \\
\hline Low erosion & 1 & 3 \\
\hline Significant erosion & 2 & 4 \\
\hline High erosion & 2 & 4 \\
\hline Very high erosion & 2 & 4 \\
\hline
\end{tabular}

The indices from 1 to 4 of the trends proposed by PAP/RAC describe the different behaviors of water erosion as follows:

1: Tendency is to stabilize, regress or limit the spatial expansion of the erosion process when the weak or very weak erosive states coincide with minor actual forms of erosion

2: The trend is towards localized expansion or intensification of the erosion process when there is a predicted erosive state that is high while the forms of erosion are minimal.

3: The trend is towards generalized expansion or intensification when the erosive states predicted by the factors studied show low erosion while actual erosion is greater and manifests itself in more dramatic forms.

4: The coincidence of an erosive state predicting potentially high erosion with major forms of erosion would indicate a trend from generalized degradation to an irreversible situation.

The map of erosion trends (figure 13) shows the dominance of the localized trend of expansion or intensification of the erosion process, which occupies more than $86 \%$ of the total surface area of the basins. Trends towards stabilization, regression or limitation of the expansion of the erosion process occupy 13\%. The trends of generalized degradation towards an irreversible situation occupy only $0.22 \%$ of the total surface area of the basins. 


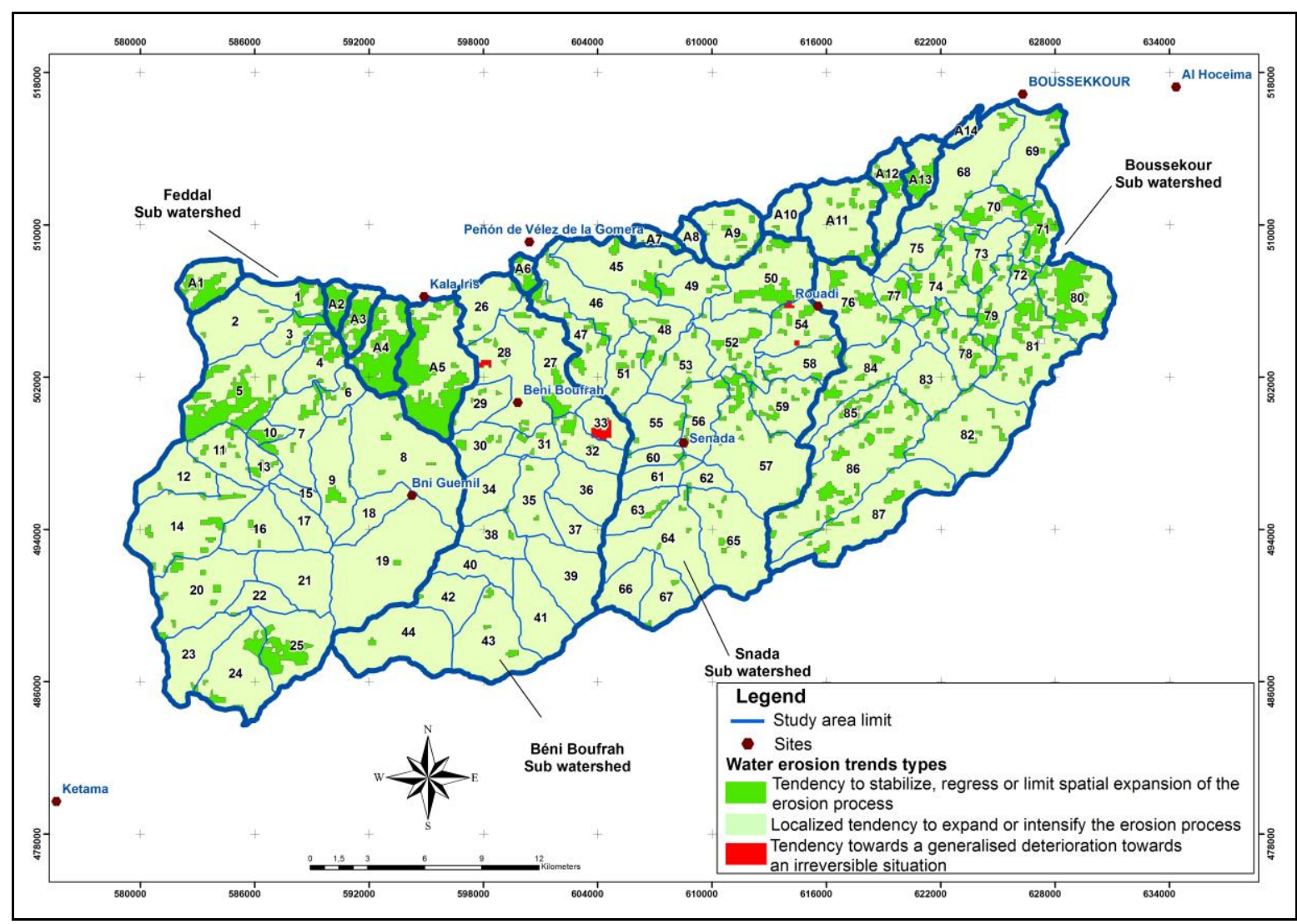

Figure 13: Map of water erosion trends in basins according to PAP/RAC

Table 14: Matrix of erosion trends according to PAP/RAC

\begin{tabular}{|r|r|r|}
\hline \multicolumn{1}{|c|}{ Trend class } & Area (ha) & \multicolumn{1}{|c|}{$\%$} \\
\hline 1 & $12,366.42$ & 13.10 \\
\hline 2 & $81,836.35$ & 86.68 \\
\hline 4 & 206.26 & 0.22 \\
\hline Total & $\mathbf{9 4 , 4 0 9 . 0 2}$ & $\mathbf{1 0 0}$. \\
\hline
\end{tabular}

The trend map is a tool to guide land-use planning decisions by describing actual erosion and its evolution over time, thus prioritizing basins into several priority areas. The indices from 1 to 4 of the trends describe an increasing erosion risk. As a result, index 4 refers to the areas with the highest priority for erosion control and control interventions. On the other hand, index 1 represents non-priority areas that represent a tendency to limit the spatial expansion of the erosion process (figure 14). The social aspect and protection of populations and infrastructures have also been taken into consideration for the prioritisation of catchment areas, the result is presented in the following map: 


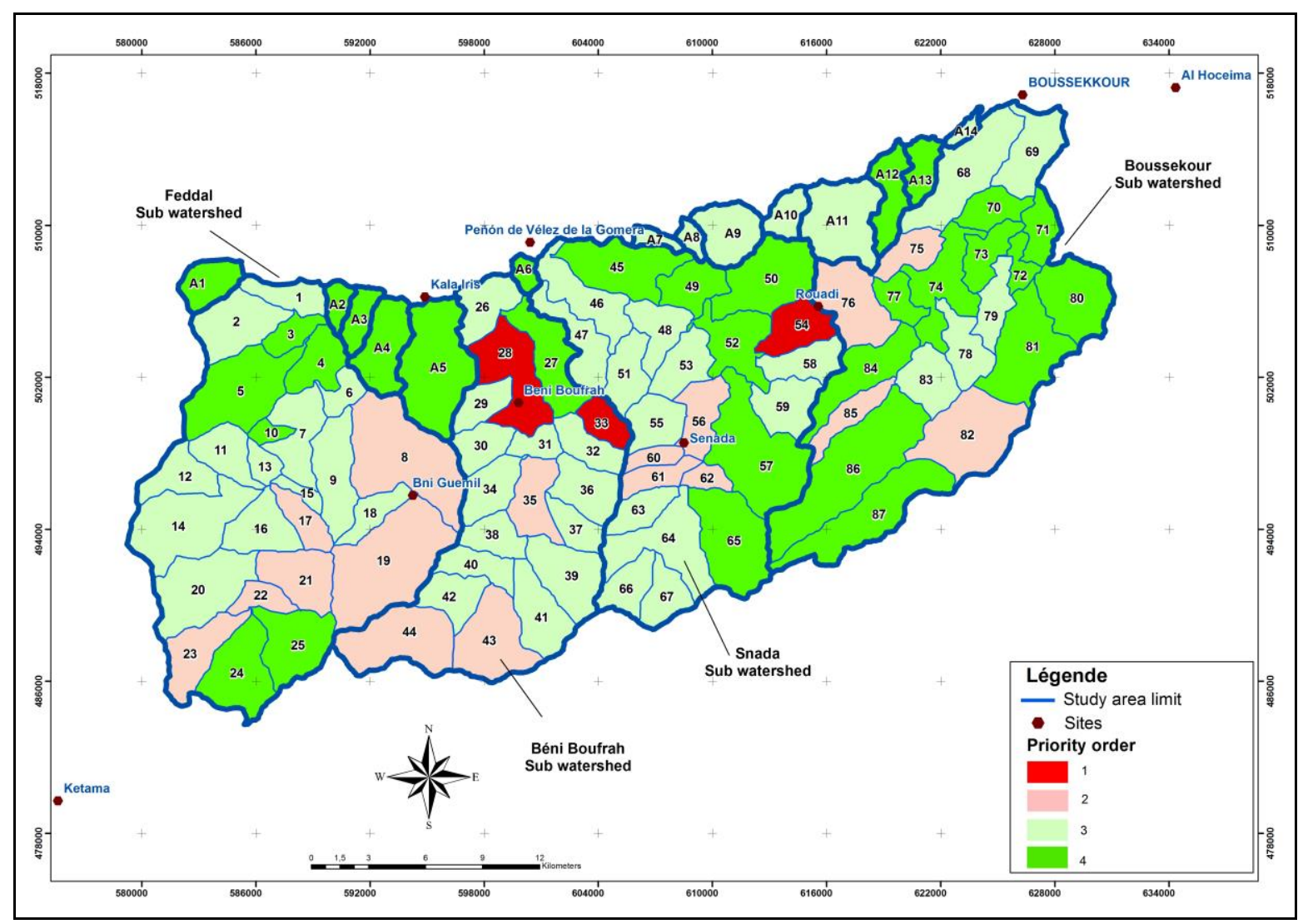

Figure 14: Map of the Hierarchy of Sub-watersheds according o Priority Order

\section{Conclusion}

Mapping and estimating water erosion using the PAP/RAC method in the watersheds made it possible to analyze and understand the problems of the study area in terms of erosion risks. For the PAP/RAC method, the first map of the so-called predictive phase of erodibility, carried out taking into account slope and lithology, showed that more than $73 \%$ of the catchment areas have sedimentary rocks or soils that are slightly or moderately compacted with Sediments or soft soil, non-cohesive and detrital material. High and moderate erodibilities occupy a relatively large portion and are in areas where the slopes are steep to moderate with weakly resistant material (marl) or weakly compacted (alluvial formation). From the point of view of vegetation cover, according to the analysis of the results, the class of intensive crops near dwellings represents $52.74 \%$, followed by that of forests with $31.51 \%$. This can be explained by the geological, morphological, and climatic nature of the study area. The map obtained shows that the location of the most important class is in the upstream part of the catchment areas. The map of erosive states is the final step in the predictive approach, provides information on the current state of degradation, and shows that the dominance of the high and notable classes (4) and (3), which are located in areas where the slope is high, and/or the lithology is of a friable nature. The low (2) and very low (1) erosion degree class occupies small areas. The descriptive approach has shown that the basins are totally exposed to the risks of erosion, this is due to the absence of dense vegetation cover, which makes the latter devoid of protected sites (stable areas) from water erosion. The integration phase complements the results obtained during the predictive phase 
with descriptive data on erosion processes. The purpose of this step is to produce the final map identifying and evaluating both potential erosion (Erosive Status) and current erosion in its different forms, intensities and evolutionary trends. The consolidated erosion map shows that more than half of the surface area of the basin $(53 \%)$ is affected by low-intensity groundwater erosion, $13 \%$ is affected by high-intensity groundwater erosion, $15 \%$ is affected by high groundwater erosion. Low intensity gutter erosion occupies 3\%, it is located along the Wadi relative to areas where the slope, and lithology favour rustle. The trend map is the final result of the integration phase, it describes the trends in the evolution of erosion in the different parts of the basin, and therefore it is a tool to guide land use planning decisions and tillage methods in order to limit the risks of water erosion in this basin.

\section{References}

Allal El Fassi. Rapport de synthèse. p: 51. PAP/CAR (1998): Directives pour la cartographie et la mesure des processus d'érosion hydrique dans les zones côtières méditerranéennes. PAP-8/PP/GL.1. Split, Programme d'actions prioritaires pour le Centre d'activités régionales du (PAM/PNUE), en collaboration avec la FAO, pp xii+72.

FALEH, A. et SADIKI, A. (2009): «Quantification de l'érosion par l'étude de l'envasement des barrages. Exemple des barrages collinaires AbdelAli et Ank Jmel au Prérif». Cahiers Géographiques n 6/2009. pp. 37-44.

MESRAR, H. (2010): Application des directives du PAP/CAR et des outils SIG pour l'évaluatioon de l'érosion hydrique et la définition des facteurs causaux dans le bassin versant de l'oued Amzaz/ Mémoire de Master, Faculté des Sciences et Techniques de Fès.

PAP/CAR, 1998 -" Directives pour la cartographie et la mesure des processus d'érosion hydrique dans les zones côtières méditerranéennes". Rapport du Centre d'activités régionales pour le Programme d'actions prioritaires.72p.

SADIKI, A., FALEH, A., ZÊZERE, J. L. et MASTASS, H. (2009): «Quantification de l'érosion en nappes dans le basin versant de l'oued Sahla, Rif central Maroc». Cahiers Géographiques n 6/2009. pp. 59-70.

SADIKI, A. (2005): Estimation des taux d'érosion et de l'état de dégradation des sols dans le bassin versant de Boussouab, Maroc nord oriental : Application du modèle empirique (USLE), de la technique du radio-isotope 137Cs et de la susceptibilité magnétique. Thèse de doctorat, Faculté des Sciences Oujda.

SADIKI, A., MESRAR, H., FALEH, A. et CHAAOUAN, J. (2012): «Modélisation et cartographie des risques de l'érosion hydrique: cas du bassin-versant de l'oued Larbaa, Maroc». Papeles de Geografía N 55-56. pp. 179-188. 